\title{
MEDIA PEMBELAJARAN LEARNING VECTOR QUANTIZATION BERBASIS MULTIMEDIA UNTUK MEMUDAHKAN PEMAHAMAN MAHASISWA DALAM MATAKULIAH JARINGAN SARAF TIRUAN
}

\author{
Cahyoko Hariya Pamilu (11018217) ${ }^{a, 1}$, Ardi Pujiyanta $(60030480){ }^{b, 2}$ \\ a,b Program Studi Teknik Informatika Universitas Ahmad Dahlan \\ J1. Ringroad Selatan, Kragilan, Tamanan, Kec. Banguntapan, Bantul,,Yogyakarta 55191 \\ ${ }^{1}$ Email: cahyokohariya@gmail.com ${ }^{2}$ email: ardipujiyanta@tif.uad.ac.
}

\section{ABSTRAK}

Materi Learning vector quantization pada mata kuliah jaringan saraf tiruan bagi sebagian mahasiswa dirasa sulit untuk dipahami. Materi learning vector quantization dirasa sulit oleh mahasiswa pada soal penyelesaian langkah-langkah menentukan pengkodean input dan target pada LVQ dan memahami vector kelas input dan mengklasifikasiannya. Untuk itu perlu dibangun aplikasi media pembelajaran Jaringan Saraf Tiruan khususnya pada materi Learning vector quantization agar dapat digunakan mahasiswa sebagai sarana belajar dan mempermudah dosen dalam menyampaikan materi.

Subyek penelitian ini adalah aplikasi multimedia sebagai media pembelajaran Learning vector quantization pada mata kuliah jaringan saraf tiruan. Pengumpulan data dalam penelitian ini menggunakan metode studi pustaka, metode interview. Aplikasi disusun dengan prosedur yang mencakup identifikasi masalah yang diperoleh, analisis kebutuhan, perancangan konsep, merancang isi, design dokumen dan diagram navigasi, merancang naskah, merancang grafis, memproduksi sistem, pengetesan sistem dengan black box dan alpha test.

Hasil penelitian ini adalah aplikasi multimedia sebagai media pembelajaran Learning vector quantization pada mata kuliah jaringan saraf tiruan bagi mahasiswa program studi teknik Informatika di Universitas Ahmad Dahlan yang berdasarkan hasil uji coba tersebut dapat disimpulkan bahwa aplikasi pembelajaran ini dapat membantu proses pembelajaran pada mahasiswa untuk memahami materi dan dapat digunakan sebagai alat bantu dosen untuk menunjang pembelajaran pada mata kuliah jaringan saraf tiruan .

\section{Ciptaan disebarluaskan di bawah lisensi CC-BY-SA.}

Kata kunci : Jaringan saraf tiruan, Learning vector quantization, Multimedia.

\section{Pendahuluan}

\subsection{Latar Belakang Masalah}

Pembelajaran merupakan kegiatan yang melibatkan berbagai macam komponen, antara lain peserta didik, pendidik, kurikulum, sarana dan prasarana pendidikan. Pendidik termasuk komponen yang sangat berpengaruh dalam proses pembelajaran, yang memiliki tanggung jawab dan sangat menentukan dalam pencapaian keberhasilan penyelenggaraan pendidikan. Sebelum melaksanakan pembelajaran, pendidik dituntut untuk memperhatikan berbagai komponen dalam sistem pembelajaran yang meliputi: penyusunan rencana pembelajaran, penyiapan materi yang relevan, merancang metode yang sesuai dengan situasi dan kondisi peserta didik, menyiapkan sumber belajar dan media. (Dwi Cahyo, Handoko. 2013)

Mata kuliah Jaringan saraf tiruan terdiri dari beberapa materi pembelajaran, salah satunya adalah metode Learning Vector Quantization. Learning Vector Quantization adalah suatu metode klasifikasi pola yang masing - masing unit output mewakili kategori atau kelas tertentu (beberapa unit output seharusnya digunakan untuk masing-masing kelas). Vektor bobot untuk 
sebuah unit output sering dinyatakan sebagai sebuah vektor referensi. Diasumsikan bahwa serangkaian pola pelatihan dengan klasifikasi yang tersedia bersama dengan distribusi awal dari vektor referensi. Sesudah pelatihan, sebuah jaringan Learning Vector Quantization mengklasifikasikan vektor input dengan menugaskan ke kelas yang sama sebagai unit output, sedangkan yang mempunyai vektor referensi diklasifikasikan sebagai vektor input. (Kairudin. 2013)

Berdasarkan hasil nilai kuis ke 11, mahasiswa yang mendapat nilai di bawah 60 ada 59,62 $\%$ atau 15 mahasiswa. Tingkat pemahaman mahasiswa lebih rendah dari kompetensi, dan motivasi mahasiswa dalam mengikuti pelajaran perlu mendapat perhatian. Hal ini terlihat dari keinginan mahasiswa untuk bertanya, mengungkapkan pemahaman mereka mengenai materi yang disampaikan masih rendah. Mahasiswa lebih banyak menunjukkan sifat pasif dalam mengikuti pelajaran.

Dengan adanya penggunaan multimedia diharapkan banyak membantu dan membuat menarik mahasiswa untuk menguasai materi learning vector quantization. Media pembelajaran ini bisa digunakan sebagai alat bantu dalam proses belajar, bisa sebagai pengganti pelajaran atau buku itu sendiri serta bisa mengevaluasi kemampuan mahasiswa dengan mengerjakan soal-soal yang telah disediakan untuk memudahkan upaya penyampaian materi tersebut.

\subsection{Batasan Masalah}

Masalah dibatasi hanya pada perancangan alat bantu belajar berupa implementasi multimedia untuk mata kuliah jaringan saraf tiruan pada materi Learning Vector Quantization Jurusan Teknik Informatika Universitas Ahmad Dahlan (UAD) berdasarkan kurikulum dan satuan acara perkuliahan (SAP) yang sudah ada di dalamnya yakni tentang metode learning vector quantization.

\subsection{Rumusan Masalah}

Berdasarkan latar belakang masalah dan batasan masalah di atas maka diperoleh rumusan masalah sebagai berikut:

1. Bagaimana membuat aplikasi multimedia sebagai media pembelajaran yang diharapkan mampu membantu dosen di dalam memudahkan menjelaskan:

a. Pengkodean input dan target pada Learning Vector Quantization.

b. Vector kelas input dan mengklasifikasiannya.

c. Perhitungan matrik pelatihan pada jaringan Learning Vector Quantization.

2. Bagaimana menguji aplikasi multimedia ini apakah dapat berjalan dengan baik dan bisa diterapkan sebagai media pembelajaran Jaringan Saraf Tiruan.

\subsection{Tujuan Penelitian}

Adapun tujuan dari penelitian ini adalah membuat media pembelajaran berbasis multimedia, Sehingga mahasiswa semakin mudah dalam memahami:

a. Pengkodean input dan target pada Learning Vector Quantization.

b. Vector kelas input dan mengklasifikasiannya.

Perhitungan matrik pelatihan pada jaringan Learning Vector Quantization. 


\section{Landasan Teori}

\subsection{Kajian Terdahulu}

Kajian penelitian terdahulu diambil dari penelitian yang dilakukan oleh Kairudin dengan judul "Media Pembelajar Jaringan Saraf Tiruan Materi Brain State In A Box Berbasis Multimedia". Penelitian ini berisi tentang pembuatan aplikasi pembelajaran menggunakan komputer berbasis multimedia yang dapat digunakan sebagai alat bantu belajar mata kuliah Jaringan Saraf Tiruan, khususnya materi Brain State in a Box, Penelitian berikutnya dilakukan dengan oleh Handoko Dwi Cahyo dengan judul "Media Pembelajaran Jaringan Saraf Tiruan Metode Kohonen Berbasis Multimedia". Dalam implementasi pembelajaran ini menampilkan sesi tutorial materi, contoh soal, serta animasi objek pada materi yang dibahas sehingga mampu memperjelas pemahaman mahasiswa. Redha Rizky Firdaus (2014) berjudul "Media Pembelajaran Jaringan Saraf Tiruan Metode Mesin Boltzman Berbasis Multimedia". Media pembelajaran ini menampilkan bentuk pengajaran dan pembelajaran yang interaktif agar lebih memudahkan dalam pemahaman materi Mesin Biltzman.

\section{Metode}

\subsection{Metode Penelitian}

Subyek penelitian pada tugas akhir ini adalah Media Pembelajaran Learning Vector Quantization Berbasis Multimedia Untuk Memudahkan Pemahaman Mahasiswa Dalam Matakuliah Jaringan Saraf Tiruan. Aplikasi media pembelajaran ini bertujuan untuk dapat membantu mahasiswa dalam menyelesaikan masalah Learning Vector Quantization pada mata kuliah Jaringan Saraf Tiruan di Universitas Ahmad Dahlan. Pada aplikasi ini menyajikan tentang:

1) Tutorial dalam bentuk materi dan animasi yang mendukung materi untuk memberi pelajaran Jaringan Saraf Tiruan khususnya metode Learning Vector Quantization.

2) Pemberian materi dan rumus-rumus Learning Vector Quantization untuk suatu masalah.

3) Penggambaran berupa animasi objek dari materi yang terkait.

\section{Hasil dan Pembahasan}

\subsection{Analisis Kebutuhan system}

\subsubsection{Analisis Kebutuhan Pengguna}

Kegiatan ini merupakan kegitan analisis terhadap kebutuhan-kebutuhan mahasiswa dan dosen pengampu dalam membangun sistem. Sistem yang dibangun dalam penelitian ini adalah program media pembelajaran mata kuliah Jaringan Saraf Tiruan materi Metode Learning Vector Quantization berbasis multimedia.

\subsubsection{Analisis kebutuhan system}

Sistem yang dibangun dalam penelitian ini adalah aplikasi media pembelajaran jaringan saraf tiruan pokok bahasan metode Learning vector Quantization menggunakan multimedia.

Sistem pada aplikasi ini dibuat untuk membantu mahasiswa dalam mempelajari materi. Media pembelajaran dapat digunakan sebagai pendamping dosen dalam menyampaikan materi pembelajaran metode Learning vector Quantization. Selain itu Sistem juga dapat melakukan beberapa hal untuk menunjang kebutuhan sistem itu sendiri antara lain :

a. Sistem akan menampilkan menu materi mengenai jaringan saraf tiruan dan Learning vector Quantization, Arsitektur Learning vector Quantization, Algoritma Learning vector Quantization dalam waktu 30 menit .

b. Sistem akan menampilkan menu simulasi yang disajikan dalam bentuk animasi perhitungan Learning vector Quantization dalam durasi waktu 20 menit.

c. Sistem akan menampilkan penyelesaian dari setiap soal pada latihan dalam durasi waktu 20 menit.

Pada evaluasi jenis soal berupa pilihan ganda, setelah selesai mengerjakan soal terdapat hasil dari mengerjakan soal serta keterangan yang menyatakan telah memenuhi target lulus atau belum. Untuk evalusi memiliki durasi waktu pengerjaan 20 menit. 


\subsection{Perancangan Sistem}

\subsubsection{Perancangan Konsep}

Dalam merancang konsep perangkat lunak, informasi yang sampai harus mempunyai tujuan yang jelas yakni untuk mempermudah mahasiswa, dimana mahasiswa mampu memilih sendiri materi yang diinginkannya, sehingga proses pemahamannya lebih mudah karena sesuai dengan keinginan. Adapun informasi yang akan disampaikan mengenai materi metode Learning vector Quantization, dimana dalam pembuatan aplikasinya melibatkan elemen-elemen multimedia yang meliputi gambaar, teks, suara dan animasi.

\subsubsection{Perancangan Menu}

Perancangan menu dapat memudahkan melihat struktur sistem yang akan dibuat. Dengan merancang menu maka dalam merancang tampilan akan lebih mudah karena sebagai petunjuk apa saja yang harus ditampilkan pada setiap halaman. Tampilan rancangan menu dapat dilihat pada gambar berikut:

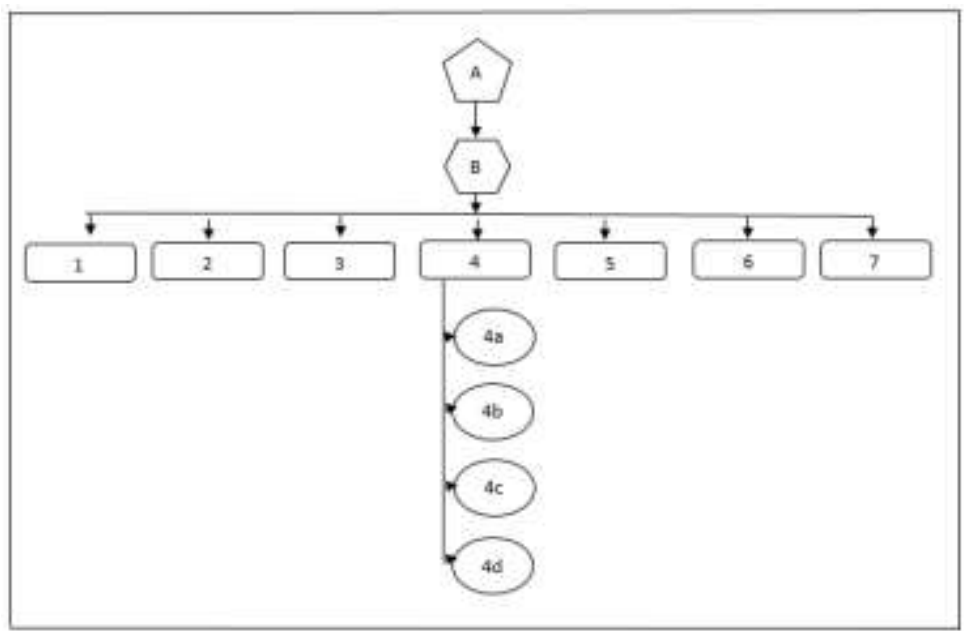

Gambar 1. Rancangan Menu

\subsection{Implementasi}

Berikut ini adalah implementasi akhir dalam pembuatan media pembelajaran jaringan saraf tiruan metode Learning vector Quantization berbasis multimedia. Dalam implementasi ini akan menjelaskan dan menampilkan gambar dari aplikasi yang telah dibuat dan juga disertakan potongan listing programnya.

\subsubsection{Tampilan Menu Utama}


Untuk tampilan menu utama dapat dilihat pada gambar 2 di bawah ini.

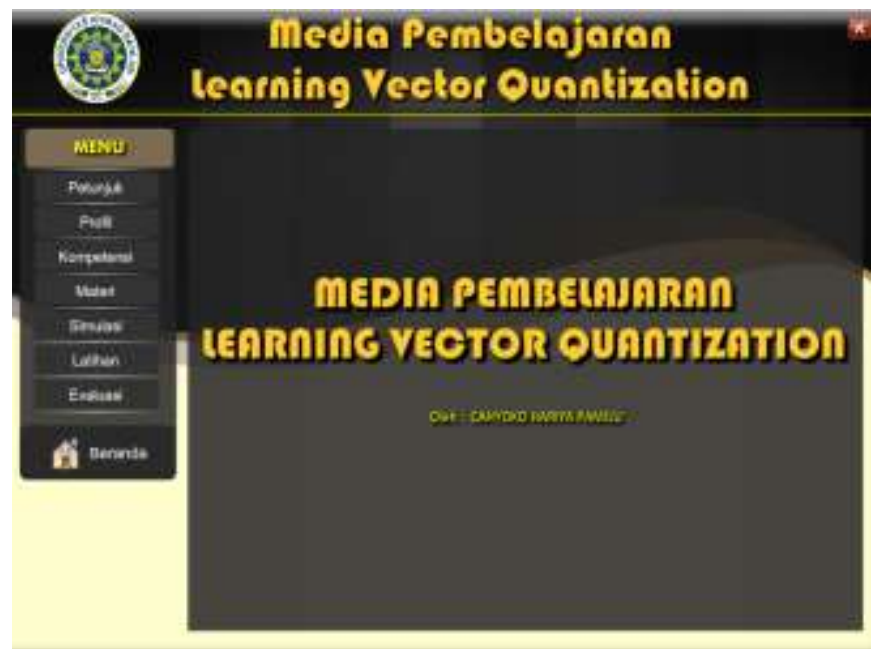

Gambar 2. Tampilan Menu Utama.

\subsubsection{Tampilan Materi}

Untuk tampilan materi dapat dilihat pada gambar 3 di bawah ini.

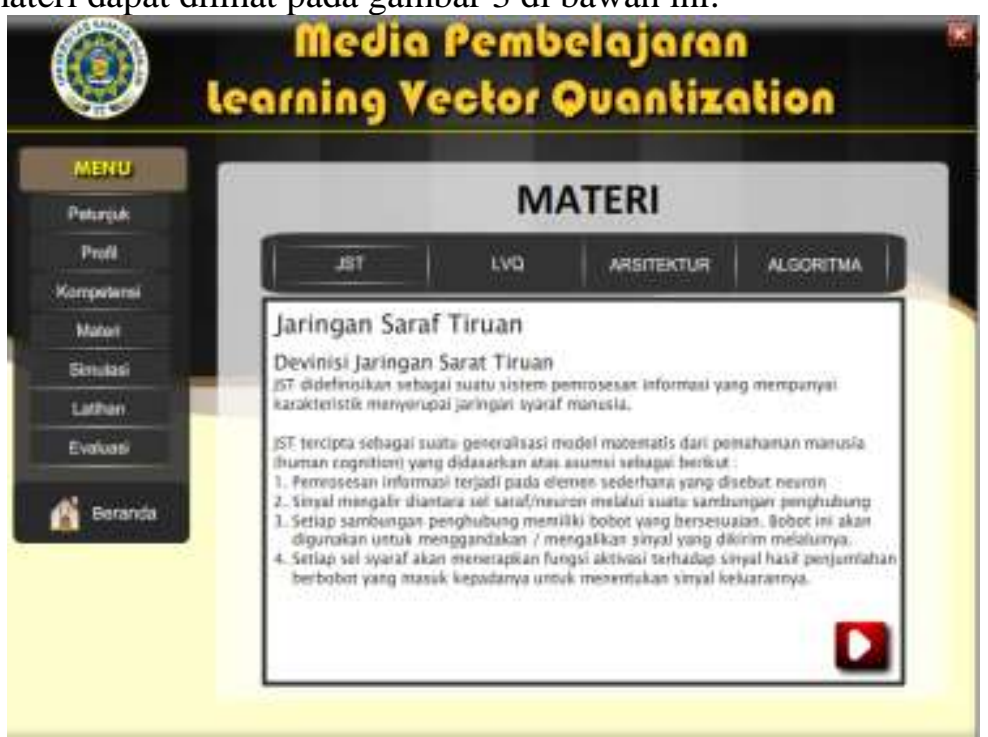

Gambar 3. Tampilan materi

\subsubsection{Tampilan Simulasi}

Untuk tampilan simulasi dapat dilihat pada gambar 4 di bawah ini. 


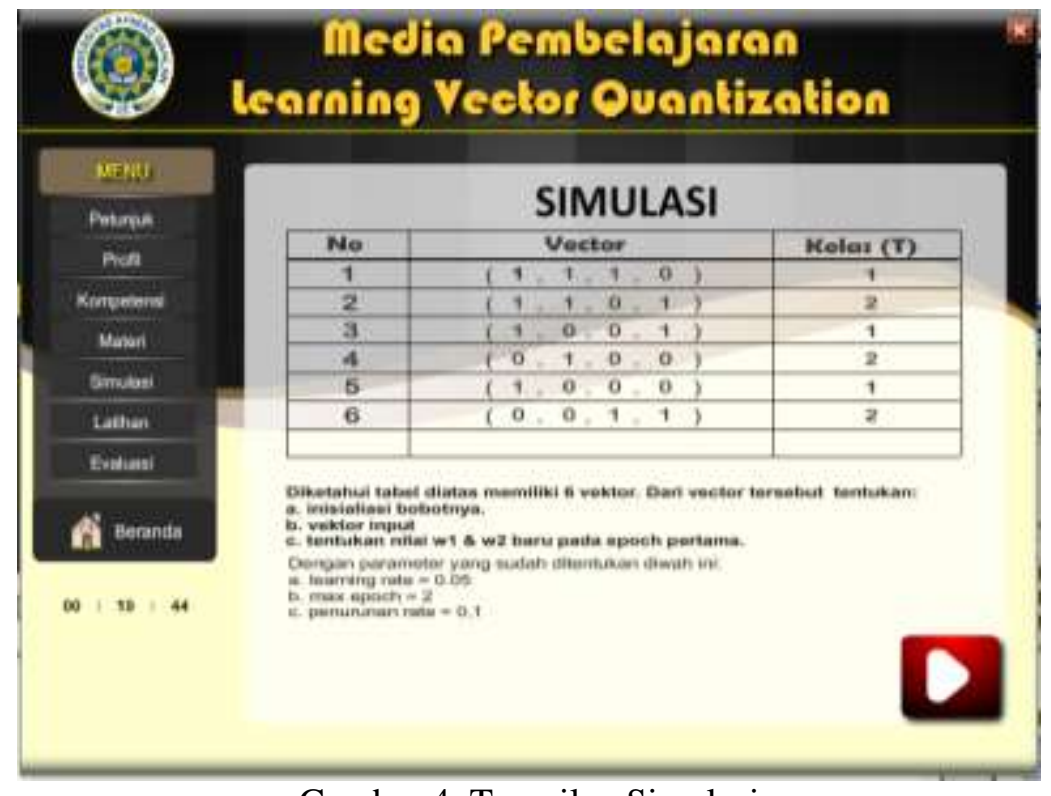

Gambar 4. Tampilan Simulasi

\subsubsection{Tampilan Latihan}

Untuk tampilan latihan dapat dilihat pada gambar 5 di bawah ini.

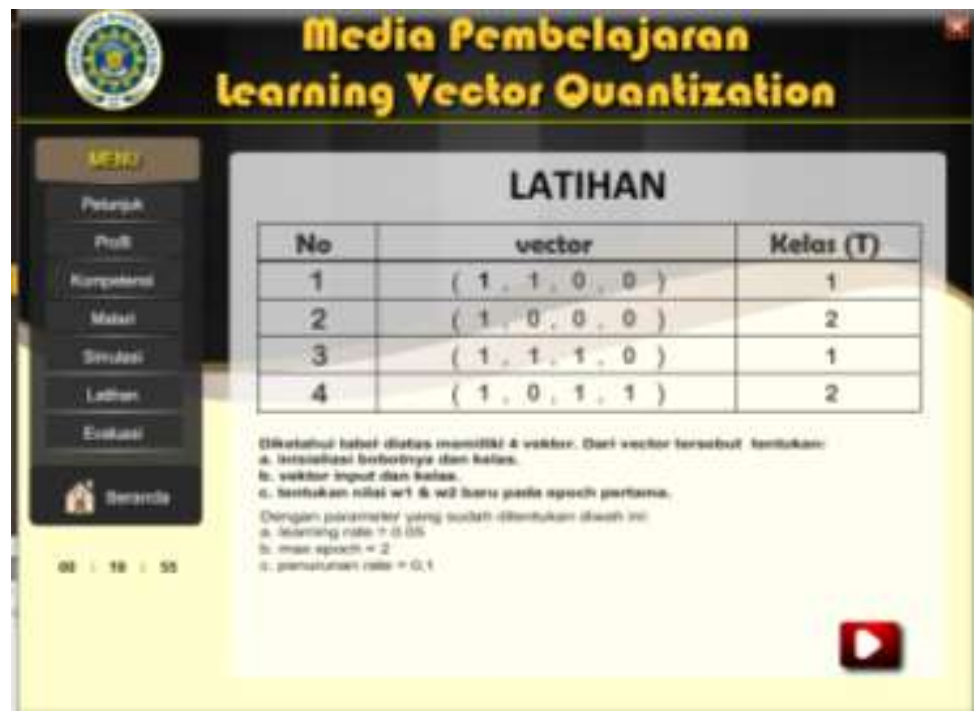

Gambar 5. Tampilan Latihan

\subsubsection{Tampilan Evaluasi}

Untuk tampilan Evaluasi dapat dilihat pada gambr 6 di bawah ini. 


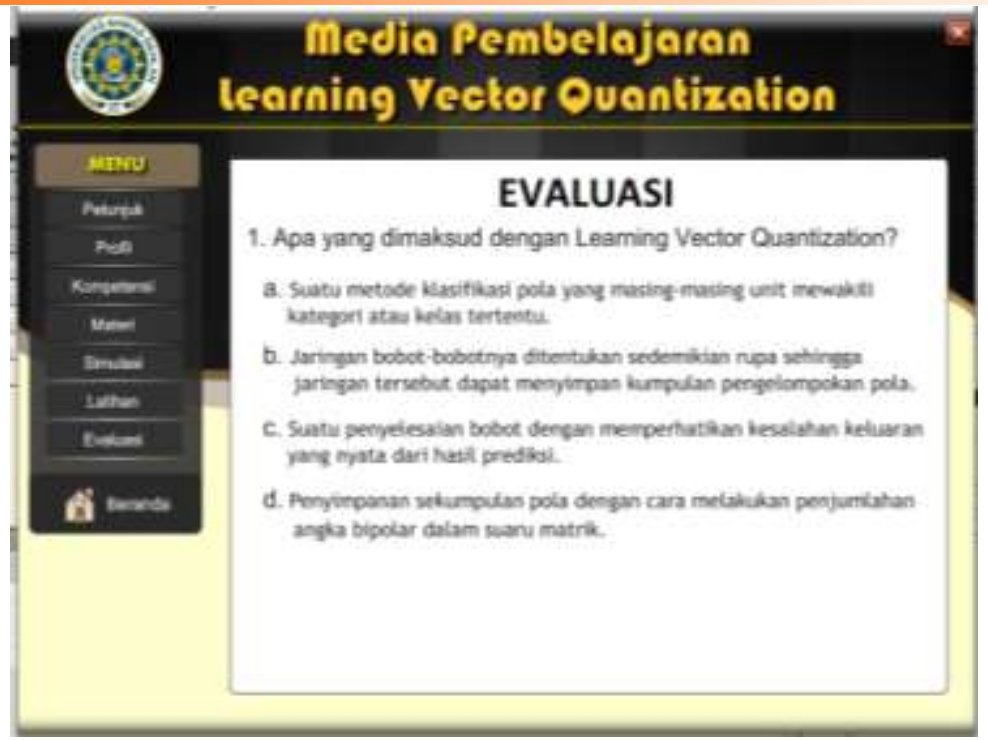

Gambar 6. Tampilan Evaluasi

\subsubsection{Tampilan Hasil Evaluasi}

Untuk tampilan HAsil Evaluasi dapat dilihat pada gambr 7 di bawah ini

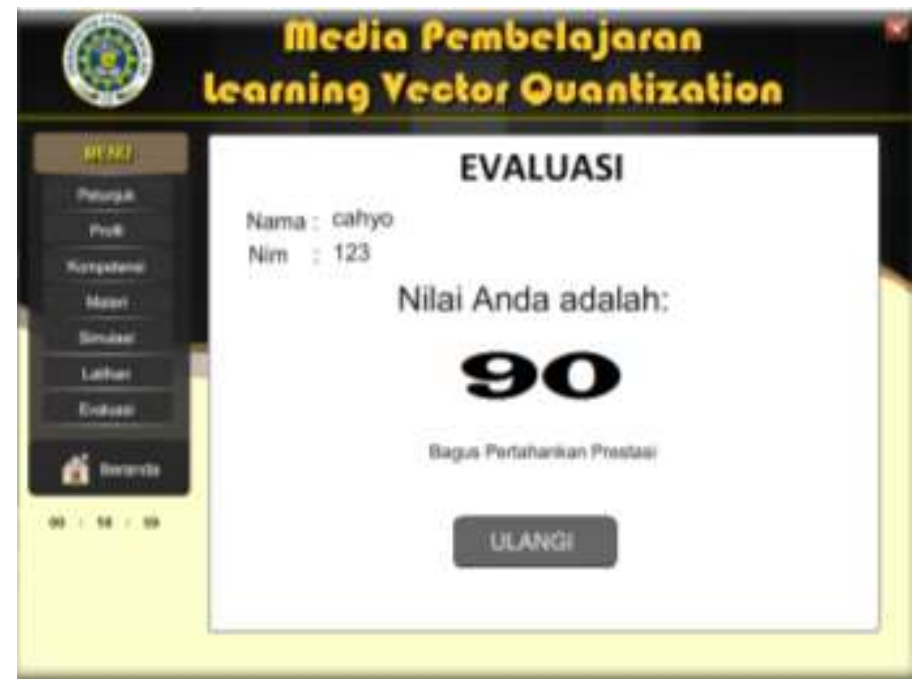

Gambar 7. Tampilan Evaluasi

\subsection{Hasil Pengujian Sistem}

Sistem ini menggunakan dua jenis pengujian yaitu:

\subsubsection{Black Box Test}

Black Box test merupakan pengujian sistem dengan cara mengamati kinerja aplikasi yang telah dibuat. Pengujian dilakukan dengan melakukan input data dan melihat output yang dihasilkan, apakah telah sesuai dengan yang diharapkan dan tidak adanya kesalahan (error) pada proses tersebut. Pengujian dilakukan oleh selaku dosen pengampu mata kuliah Jaringan Saraf Tiruan. Berdasarkan hasil dari Black Box Test, maka diperoleh persentase penilaian sebagai berikut:

$$
\begin{aligned}
& \text { Ya }=\frac{\text { Jumlah jawaban Ya }}{\text { Jumlah soal }} \times 100 \%=\frac{18}{19} \times 100 \%=95 \% \\
& \text { Tidak }=\frac{\text { Jumlah jawaban tidak }}{\text { Jumlah soal }} \times 100 \%=\frac{1}{19} \times 100 \%=5 \%
\end{aligned}
$$


Dari hasil penilaian persentase tersebut dapat diambil kesimpulan bahwa fungsi media pembelajaran dan materi yang disampaikan sudah sesuai dengan kebutuhan dosen pengampu, serta menu yang terdapat pada aplikasi seperti menu materi, latihan, dan menu simulasi telah berfungsi dengan baik yaitu dapat membantu untuk belajar mengenai metode Learning vector Quantization. Dan aplikasi layak untuk digunakan sebagai alternative media bantu dalam mempelajari materi Learning vector Quantization.

\subsubsection{Alfa Test}

Pengujian sistem menggunakan alpha test bertujuan untuk menguji kelayakan media pembelajaran sebagai alat bantu agar pembelajaran lebih efektif dan menarik sehingga diharapkan dapat meningkatkan pemahaman mahasiswa. Pengujian ini dilakukan oleh Mahasiswa bagi yang telah mengambil mata kuliah Jaringan Saraf Tiruan yang berjumlah 9 orang dengan mencoba menjalankan aplikasi media pembelajaran yang telah dirancang. Saat mencoba aplikasi hasil pengamatan berupa durasi waktu pada setiap menu yang ada pada aplikasi dan skor evaluasi dicatat untuk mendapatkan total berapa lama waktu menggunakan aplikasi dan sebagai acuan kesesuaian aplikasi dengan skenario pembelajaran dikelas. Setelah uji coba selesai kemudian membagikan angket pertanyaan kuisioner pada setiap siswa yang telah mencoba aplikasi media pembelajaran. Jumlah responden adalah 9 (dua puluh) orang dan jumlah pertanyaan yang diberikan sebanyak 11 (sebelas) pertanyaan, jadi jumlah total skor adalah 100 (Seratus). Dari hasil pengujian tersebut diperoleh prosentase sebagai berikut:

$$
\begin{array}{llr}
\text { 1) } & \text { Sangat Setuju (SS) } & : 11 / 100 \times 100 \%=11 \% \\
\text { 2) } & \text { Setuju (S) } & : 79 / 100 \times 100 \%=79 \% \\
\text { 3) } & \text { Kurang Setuju (KS) } & : 1 / 100 \times 100 \%=9 \% \\
\text { 4) } & \text { Tidak Setuju (TS) } & 100 \%=1 \%
\end{array}
$$

Dari hasil penilaian persentase tersebut dapat ditarik kesimpulan bahwa pembuatan aplikasi pembelajaran sudah sesuai dengan kebutuhan user dan aplikasi layak untuk digunakan sebagai alternatif media bantu dalam mempelajari materi Learning vector quantization pada matakuliah Jaringan Saraf Tiruan.

\section{Kesimpulan dan Saran}

\subsection{Kesimpulan}

Berdasarkan hasil penelitian dan pembahasan yang telah dilakukan, maka diperoleh beberapa kesimpulan sebagai berikut :

1. Telah dibuat aplikasi media pembelajaran mengenai metode learning vector quanatization yang dapat meningkatkan minat belajar mahasiswa dalam:

a. Pengkodean input dan target pada Learning Vector Quantization.

b. Vector kelas input dan mengklasifikasiannya.

c. Perhitungan matrik pelatihan pada jaringan Learning Vector Quantization.

2. Telah dilakukan uji coba aplikasi yang menunjukkan bahwa aplikasi yang telah dibuat sesuai dengan kebutuhan mahasiswa dan dosen di Program study Teknik Informatika di Universitas Ahmad Dahlan.

\subsection{Saran}

Beberapa saran yang dapat diberikan untuk pengembangan aplikasi ini adalah sebagai berikut : 
a. Kembangkan media pembelajaran ditambah video simulasi agar lebih mudah lagi untuk dipahami

b. Kembangkan media pembelajaran untuk latihan agar bias random dalam memilih soal latihannya.

\section{DAFTAR PUSTAKA}

Dwi Cahyo, Handoko. 2013 "Media Pembelajaran Jaringan Saraf Tiruan Metode Kohonen Berbasis Multimedia", http://e-jurnalpenelitian.blogspot.co.id/2015/03/jurnal-teknik-informatika_media_25.html.

Kairudin. 2013 "Media Pembelajarjaringan Saraf Tiruan Materi Brain State In A Box Berbasis Multimedia", http://journal.uad.ac.id/index.php/JSTIF/article/view/2505.

Ceria Agustina, Alfa. 2011 "Pengenalan Aksara Jawamenggunakan Learning Vector Quantization (Lvq)”, Skripsi S-1, Universitas Kristen Duta Wacana.

Ananggadipa, Gilang. 2014 "Pengenalan Huruf Alfabet Menggunakan Tujuh Invarian Momen Hu Dan Jaringan Saraf Tiruan Lvq (Learning Vector Quantization )", http://ejournal-s1.undip.ac.id/index.php/transient/article/view/7181.

Eka Ratnawati, Dian. 2014 "Pengembangan Metode Klasifikasi Berdasarkan K-Means Dan Lvq”, Skripsi S-1, Universitas Brawijaya.

Sutopo, Hadi. 2012 "Pengembangan Evaluasi Pembelajaran Berbasis Multimedia Dengan Flash, Php, Dan My Sql”, Skripsi S-1, Universitas Persada Indonesia YAI. 